\title{
Characterization and expression analysis of Toll-interacting protein in common carp, Cyprinus carpio L., responding to bacterial and viral challenge
}

\author{
Shijuan Shan ${ }^{\dagger}$, Lei Wang ${ }^{\dagger}$, Fumiao Zhang, Yaoyao Zhu, Liguo An ${ }^{*}$ and Guiwen Yang ${ }^{*}$
}

\begin{abstract}
Toll-interacting protein (Tollip) is a mediator involved in the TLRs signaling pathway which is critical for innate immune response. In the present study, a full-length Tollip cDNA was first cloned from common carp (CcTollip), which was $1284 \mathrm{bp}$ in length, containing an open reading frame of 831 bp encoding a peptide of 276 amino acids. Multiple sequence alignment showed that the CcTollip shared the highest similarity with that of grass carp and zebrafish. Phylogenetically, the CCTollip clustered together well with their piscine family members. Quantitative real-time PCR analysis indicated that CcTollip was widely expressed in all tissues tested and showed up-regulation with challenges of Vibrio anguillarum and poly $(\mathrm{l}: \mathrm{C})$, suggesting that CCTollip was activated by V. anguillarum and poly(l:C). These data indicated that CcTollip might play an important role in immune response to bacterial and viral invasion.
\end{abstract}

Keywords: Tollip, Common carp (Cyprinus carpio L.), Molecular cloning, Vibrio anguillarum, Poly(l:C)

\section{Background}

Common carp (Cyprinus carpio L.) is an important aquaculture fish species worldwide, but many bacterial and viral infections have recently become a big problem in common carp aquaculture industry. A better understanding of the innate immune response in common carp against bacteria and virus is critical for the sustainable growth of the industry. In the innate immunity, the recognition of bacteria or virus by host cells is mediated by multiple pattern recognition receptors (PRRs), including Toll-like receptors (TLRs), NOD-like receptors (NLRs) and RIG-I-like receptors (RLRs). Among these PRRs, TLRs could recognize both bacteria and virus (Zhang and Gui 2012; Zhang et al. 2014).

Toll interacting protein (Tollip) is an important mediator in the innate immune responses induced by TLRs

\footnotetext{
*Correspondence: an.liguo58@gmail.com; yanggw@sdnu.edu.cn †'Shijuan Shan and Lei Wang contributed equally to this work Shandong Provincial Key Laboratory of Animal Resistance Biology, College of Life Science, Shandong Normal University, Jinan 250014, People's Republic of China
}

(Zhang and Ghosh 2002). It is first identified as a member of IL-1R pathway, which is presented in a complex with IRAK1 and inhibits IL-1-induced signaling by blocking IRAK1 phosphorylation (Burns et al. 2000). Because of the significant homology in the intracellular portion of TLRs and IL-1Rs, Tollip was also found to be involved in TLR-mediated signaling (Zhang and Ghosh 2002), which could associate directly with TLR2 or TLR4 and inhibit TLR-mediated cellular responses by suppressing phosphorylation and kinase activity of IRAK1. Tollip is the first direct substrate of IRAK1, and could be phosphorylated by activated IRAK1 upon stimulation with lipopolysaccharide (LPS) or IL-1 (Zhang and Ghosh 2002). Didierlaurent et al. reported that Tollip regulated the magnitude and kinetics of IL-6 and TNF- $\alpha$ production upon stimulation with IL- $1 \beta$ and low doses or physiological doses of LPS (Didierlaurent et al. 2006).

Besides the functions in mediating the innate immune responses, Tollip was also found to participate in protein sorting. Yamakami et al. described that the interaction of Tollip with Tom1, Ubiquitin and 
Clathrin in a high molecular mass complex involved in protein sorting (Yamakami et al. 2003; Yamakami and Yokosawa 2004). Katoh et al. suggested the similar result in their study, in which they found that Tollip and Tom 1 formed a complex and regulated endosomal trafficking of ubiquitinated proteins (Katoh et al. 2004). Tollip is also involved in the nuclear translocation of proteins either as a sumoylation cofactor or a ligase (Ciarrocchi et al. 2009). Furthermore, Brissoni et al. clarified that Tollip is required in the sorting of the IL-1RI in the late endosomes (Brissoni et al. 2006). In addition, there is much information about the role of Tollip in some diseases nowadays (Liu et al. 2014a, b; Mukherjee and Biswas 2014; Shimizu et al. 2014). Tollip induces tolerance to the normal enteric flora by its up-regulated expression in intestinal epithelial cells (Melmed et al. 2003; Shibolet and Podolsky 2007). Maillard et al. reported that Tollip played an essential role on colitis susceptibility in mice (Maillard et al. 2014).

To date, the Tollip cDNA has been identified in many species including Atlantic salmon, rainbow trout, grass carp, grouper and Yesso scallop (Rebl et al. 2008; Huang et al. 2012; Li et al. 2015; Wei et al. 2015; Zhang et al. 2015). In these species, Tollip was found to participate in virus and bacteria induced immune responses. However, no information is known about the role of Tollip in innate immune response of common carp. In the present study, we first isolated and characterized the full-length cDNA of Tollip from common carp (named CcTollip), and examined the $C c$ Tollip mRNA expression patterns in various tissues under normal conditions. Furthermore, we analyzed the expression profile of the Tollip after stimulation with Vibrio anguillarum-one of the main fish pathogens and poly(I:C). These results implied that CcTollip might participate in the common carp immune response.

\section{Methods}

\section{Fish rearing and tissue collection}

Healthy common carp (C. carpio L.), with an average of $80 \mathrm{~g}$, were collected from Fresh Water Fishery Research Institute of Shandong Province. The fish were cultured at $20{ }^{\circ} \mathrm{C}$ in circulating tap water and fed daily to satiation with commercial fish feed for more than 1 week prior to experimental use. Then the liver, spleen, gills, skin, muscle, head kidney, foregut, hindgut, buccal epithelium, brain and gonad were isolated for RNA extraction.

The protocol in this study was approved by the Ethics Committee on Animal Experiments of Medical School of Shandong University (Permit Number: ECAESDUSM 1420123009). All operations were performed under anesthesia, and all efforts were made to minimize suffering of the fish.

\section{RNA extraction and CDNA synthesis}

Total RNA was isolated from various tissues, as mentioned above, using the RNAsimple Total RNA Kit (TIANGEN, China) according to the manufacturer's protocols. The RNA template was reverse transcribed into first-strand cDNA by using FastQuant RT Kit (With gDNase) (TIANGEN, China) following the manufacturer's instructions.

\section{Molecular cloning of Tollip gene}

To clone Tollip gene from common carp, a pair of primers (Table 1) were designed based on the conserved region of reported Tollip sequences. The PCR template was synthesized by spleen-derived RNA of common carp. A 518 bp cDNA fragment of common carp Tollip was obtained by PCR using the cDNA templates. PCR program for amplification of common carp Tollip fragment was carried out under the following steps: initial denaturation was performed at $94{ }^{\circ} \mathrm{C}$ for $3 \mathrm{~min}$, followed by 33 cycles at $94{ }^{\circ} \mathrm{C}$ for $30 \mathrm{~s}, 59^{\circ} \mathrm{C}$ for $30 \mathrm{~s}$, and $72{ }^{\circ} \mathrm{C}$ for $40 \mathrm{~s}$, then a further $10 \mathrm{~min}$ extension step at $72^{\circ} \mathrm{C}$.

Then we obtained the full-length cDNA sequence of CcTollip using the RACE (Rapid amplification of cDNA ends). The $3^{\prime}$-RACE and $5^{\prime}$-RACE were performed using the $3^{\prime}$-full RACE core set (TaKaRa, Japan) and $5^{\prime}$-full RACE core set (TaKaRa, Japan) respectively following the manufacturer's protocol. Two rounds of PCR were performed to amplify the $5^{\prime}$ and $3^{\prime}$ flanking regions, the primers and annealing temperatures were shown in Table 1.

All PCR fragments were purified by PCR purification kit (TIANGEN, China). The PCR products were cloned into the pMD18-T vector (TaKaRa, Japan) and then transformed into competent Escherichia coli DH5 $\alpha$ cells. The selected single colonies were sequenced by BGI China. The $5^{\prime}$ and $3^{\prime}$ flanking regions were assembled with the known sequence.

\section{Sequence and bioinformatics analysis}

The Tollip sequence was analyzed by BLAST program (http://blast.ncbi.nlm.nih.gov/Blast.cgi) at the NCBI server (www.ncbi.nlm.nih.gov/Structure/cdd/). The multiple sequence alignment of Tollip protein between common carp and other species was performed by Clustal W method. The conserved domain structures of Tollip were predicted by the SMART online software (http:// smart.embl-heidelberg.de/). Phylogenetic tree was constructed based on the multiple sequence alignment with the full-length amino acid sequences of known Tollip using neighbor-joining method in MEGA 6.0 software program. Bootstrap sampling was reiterated 1000 times. The GenBank accession numbers or references for these sequences were shown in Additional file 1: Table S1. 
Table 1 Primers used in this study

\begin{tabular}{|c|c|c|c|}
\hline Primer & Sequence $\left(5^{\prime}-3^{\prime}\right)$ & Application & Annealing temperature $\left({ }^{\circ} \mathrm{C}\right)$ \\
\hline ToF & CTTGGGTATGCCGTCTAT & Amplification of Tollip cDNA & 59 \\
\hline ToR & GTGCGAATCACCTCCTTA & Amplification of Tollip cDNA & 59 \\
\hline GSP3'-1 & CAGCCTGTGGTCCTGATG & 3'RACE specific out primer & 55 \\
\hline GSP3'-2 & CCTGCTGTTACATCACAGA & 3'RACE specific inner primer & 55 \\
\hline GSP5'-1 & GGTTCCCTCTCGCAGGCTCTCT & 5'RACE specific out primer & 55 \\
\hline GSP5'-2 & ACGCCCTCTCATCGAAGATTTC & 5'RACE specific inner primer & 55 \\
\hline $\mathrm{U}^{\prime}-1$ & TACCGTCGTTCCACTAGTGATTT & $3^{\prime}$ RACE universal out primer & 55 \\
\hline$U 3^{\prime}-2$ & CGCGGATCCTCCACTAGTGATTTCACTATAGG & $3^{\prime}$ RACE universal inner primer & 55 \\
\hline$U 5^{\prime}-1$ & CATGGCTACATGCTGACAGCCTA & 5'RACE universal out primer & 55 \\
\hline$U 5^{\prime}-2$ & CGCGGATCCACAGCCTACTGATGATCAGTCGATG & $5^{\prime}$ RACE universal inner primer & 55 \\
\hline S11F & CCGTGGGTGACATCGTTACA & Real-time PCR for S11 & 60 \\
\hline S11R & TCAGGACATTGAACCTCACTGTCT & Real-time PCR for S11 & 60 \\
\hline RT-TF & CCGTCTCAGCATCACCGTCGTA & Real-time PCR for Tollip & 60 \\
\hline RT-TR & TCGCTCCGTTGTGGGCAGTAG & Real-time PCR for Tollip & 60 \\
\hline $\mathrm{IL}-1 \beta \mathrm{F}$ & GCTCGGCTTCATCTTGGAGAATGT & Real-time PCR for IL-1 $\beta$ & 60 \\
\hline$I L-1 \beta R$ & GCAAGGTGAGGCTGGTCTTATTGT & Real-time PCR for IL-1 $\beta$ & 60 \\
\hline IL-6F & TGAAGACAGTGATGGAGCAGCAGA & Real-time PCR for IL-6 & 60 \\
\hline $\mathrm{IL}-6 \mathrm{R}$ & CCTCACAGCAATGTGGCGAACA & Real-time PCR for IL-6 & 60 \\
\hline
\end{tabular}

\section{Immune challenges}

The challenge experiments were divided into the bacterial (V. anguillarum) challenged group and the poly(I:C) challenged group.

For bacterial challenge, V. anguillarum (CCTCCM204067 strain) obtained from the China Center for Type Culture Collection, was incubated at $28^{\circ} \mathrm{C}$ overnight in Luria-Bertani medium containing $3 \% \mathrm{NaCl}$ with shaking. The protocols were performed as previously described (Li et al. 2013, 2014; Yang et al. 2014). The $V$. anguillarum was inactivated in $0.5 \%$ formalin at $4{ }^{\circ} \mathrm{C}$ overnight. The inactivated $V$. anguillarum was suspensed in sterile $0.1 \mathrm{M}$ phosphate buffered saline (PBS) at $2 \times 10^{8} \mathrm{CFU}$. The fish was challenged by intraperitoneal (i.p.) injection with $500 \mu \mathrm{l}$ inactivated $V$. anguillarum. After challenge, all the fish were placed in a rectangular tank of fresh water. Sampling was performed 6,12, 24 and $48 \mathrm{~h}$ after challenge, with three fish in each group, while fish in the control group were injected with the same amount of phosphate buffered saline (PBS).

Poly(I:C) (SIGMA, USA) dissolved in sterile PBS, was adjusted to $1.6 \mathrm{mg} / \mathrm{ml}$. The fish was injected with poly(I:C) at $500 \mu \mathrm{l}$ per fish by intraperitoneal (i.p.) injection. According to the results of our previous experiments, injection with PBS cannot up-regulate the expression of Tollip gene in common carp, and the expression level was similar to that in un-challenged fish. Thus, we used un-challenged fish as the control in the study. Seven immune-related tissues: liver, spleen, head kidney, hindgut, foregut, gills and skin were sampled and kept in liquid nitrogen for total RNA extraction.

\section{Isolation of head kidney leukocytes}

Head kidney leucocytes (HKL) isolation and culture were performed based on the protocol described by Joerink et al. (2006). Head kidneys were aseptically excised and placed in a $100 \mathrm{~m}$ nylon cell strainer. Head kidneys were gently pressed with a plunger through a 100 -m sterile nylon mesh and rinsed with PBS. Cell isolation was performed using a 51/34 \% non-continuous percoll gradient (Sigma-Aldrich). After $25 \mathrm{~min}$ centrifugation at $800 \times g$, the cells present in the interface of the gradient were collected and washed three times with PBS. The cells were resuspended in complete L-15 (Gibco) (supplemented with $5 \%$ FBS, $100 \mathrm{U} / \mathrm{ml}$ penicillin, and $100 \mu \mathrm{g} / \mathrm{ml} \mathrm{strep-}$ tomycin). About $10^{7}$ cells/well were seeded in 24-well plate with $500 \mu \mathrm{l}$ complete mediums. After recovering overnight at $25^{\circ} \mathrm{C}$, drug treatment was performed using lipopolysaccharide (LPS) (10 $\mu \mathrm{g} / \mathrm{ml}$, Sigma-Aldrich). Then the cells were collected at 3, 6, 9, 12 and 24 h. Total RNA was isolated from the HKLs and qPCR was performed with the gene-specific primers (Table 1 ) to evaluate the mRNA levels of Tollip, IL-1 $\beta$, and IL-6.

\section{Quantitative real-time PCR}

Real-time PCR was performed in triplicate for each sample on an iQ5 Real-time PCR instrument (Bio-Rad) using SYBR Green Real Master Mix (TIANGEN, China). 40S 
ribosomal protein S11 gene served as an internal reference gene to normalize the mRNA expression in different tissues as previous studies described (Engelsma et al. 2001). The primers that were used have been shown in Table 1. Reaction conditions were as follows: incubated for $1 \mathrm{~min}$ at $94{ }^{\circ} \mathrm{C}$, followed by 40 cycles of $20 \mathrm{~s}$ at $94{ }^{\circ} \mathrm{C}$, $20 \mathrm{~s}$ at $59{ }^{\circ} \mathrm{C}$ and $50 \mathrm{~s}$ at $70{ }^{\circ} \mathrm{C}$. The PCR data were analyzed using $2^{(-\Delta \Delta \mathrm{Ct})}$ method.

\section{Statistical analysis}

Standard deviations were calculated using the relative expression ratios of 3 replicates for each gene measured. Data were analyzed with the Graphpad Prism 5 software, with two-way analysis of variance (ANOVA), and statistical significance was defined as $p<0.05$.

\section{Results}

\section{Cloning and sequence characterization of CcTollip}

The full-length cDNA of CcTollip was 1284 bp containing 92 bp $5^{\prime}$-untranslated region (UTR), an open reading frame (ORF) of $831 \mathrm{bp}$ encoding a peptide of 276 amino acids and a $361 \mathrm{bp} 3^{\prime}$-UTR. The poly (A) tail was at $361 \mathrm{bp}$ downstream of stop codon TAG. The polyadenylation signal ATTAAA was located 20 bp upstream of the poly (A) tail (Additional file 2: Fig. S1). The Tollip sequence was deposited in GenBank under accession no. KF660221. Conserved domain analysis with SMART program showed that $C c$ Tollip contained a TBD (Tom1binding domain) extending from Met-1 to Arg-54, a C2 (conserved core domain 2) domain extending from Leu55 to Trp-151, and a CUE (coupling of ubiquitin to endoplasmic reticulum degradation) domain extending from Cys-231 to Ala-273 (Fig. 1).

\section{Alignment and phylogenetic analysis}

The deduced amino acid sequences of Tollip were compared between common carp and other species (Additional file 3: Table S2). The CcTollip shared the highest similarity with the Tollip of zebrafish $(93.8 \%)$ and grass carp (93.1\%), whereas a low similarity to Xenopus tropicalis $(79.9 \%)$. The multiple sequence alignment of Tollip between common carp and the other species showed that the sequences of TBD, C2 domain and the CUE domain remained more conserved than the other regions (Fig. 1). To further investigate the evolutionary relationship of Tollip, the phylogenetic tree was generated, which showed that the $C c$ Tollip was clustered with other bony fish Tollip and it was most closely related to the grass carp and zebrafish Tollip (Fig. 2), suggesting that the direction of Tollip protein evolution was consistent with the evolution of species.

\section{Expression profile of CcTollip}

In order to analyze the CcTollip expression profile, the relative expression of $C c$ Tollip gene was detected in 11 tissues of healthy common carp (Fig. 3). The results showed that the $C c$ Tollip was predominantly detected in brain, followed by gonad, gills, spleen, head kidney, hindgut, muscle, foregut and liver, and the lowest expression levels were found in buccal epithelium and skin.

\section{The temporal expression of CcTollip after stimulation with V. anguillarum}

To investigate the potential role of CcTollip in response to bacterial and viral infections, the expression profile of $C c$ Tollip in various tissues after $V$. anguillarum (Fig. 4) and poly(I:C) stimulation (Fig. 5) was determined.

After stimulus with $V$. anguillarum, the expression of CcTollip gene in liver, spleen, hindgut, skin and gills was up-regulated, and then gradually decreased over time. The expression level of $C c$ Tollip in liver was induced and reached the peak at $6 \mathrm{~h}$ (about 4.15-fold; $p<0.001$ ) (Fig. 4a). In spleen, hindgut, gills and skin, the level of Tollip transcripts started to increase at $6 \mathrm{~h}$ and reached the maximum at $12 \mathrm{~h}$ (5.16-fold, 3.42-fold and 3.73-fold, 4.77 -fold respectively; $p<0.001$ or $p<0.01$ ) (Fig. 4b, $\mathrm{e}-\mathrm{g})$. However, the expression level of Tollip in head kidney and foregut had no change after stimulation with $V$. anguillarum (Fig. 4c, d).

\section{The temporal expression of $C c$ Tollip after stimulation with poly(I:C)}

After challenge with poly(I:C), the $C c$ Tollip gene expression in liver and spleen was up-regulated and reached to peak at $12 \mathrm{~h}$ (5.33-fold and 8.61-fold, $p<0.01$ ) (Fig. 5a, b). In head kidney, hindgut and gills, the peak of Tollip gene expression was observed at $24 \mathrm{~h}$ after challenge, which were 2.81 -fold, 3.56 -fold and 3.26-fold ( $p<0.05$ or $p<0.01$ ), respectively (Fig. $5 \mathrm{c}, \mathrm{e}, \mathrm{f}$ ). The highest induction level of Tollip in foregut and skin was both at $48 \mathrm{~h}$ after challenge, 3.95 -fold and 4.95 -fold $(p<0.001$ or $p<0.05$ ) were observed, respectively (Fig. 5 d, g).

\section{Expression profile of CcTollip, IL-1 $\beta$ and IL- 6 in HKLs}

In order to study the correlation of Tollip and proinflammatory cytokines, we isolated the head kidney leukocytes. It was found that the expression of Tollip, IL-1 $\beta$ and IL- 6 presents fluctuation after LPS stimulation. The expression of Tollip arrived at the highest value at $6 \mathrm{~h}$, with a 1.4-fold of the control group $(p<0.05)$ (Fig. 6a). While the IL- $1 \beta$ and IL- 6 mRNA expression reached the highest level at $9 \mathrm{~h}$, which were 2.06 -fold and 2.07-fold of the control group, respectively $(p<0.001)$ (Fig. 6a, b). 


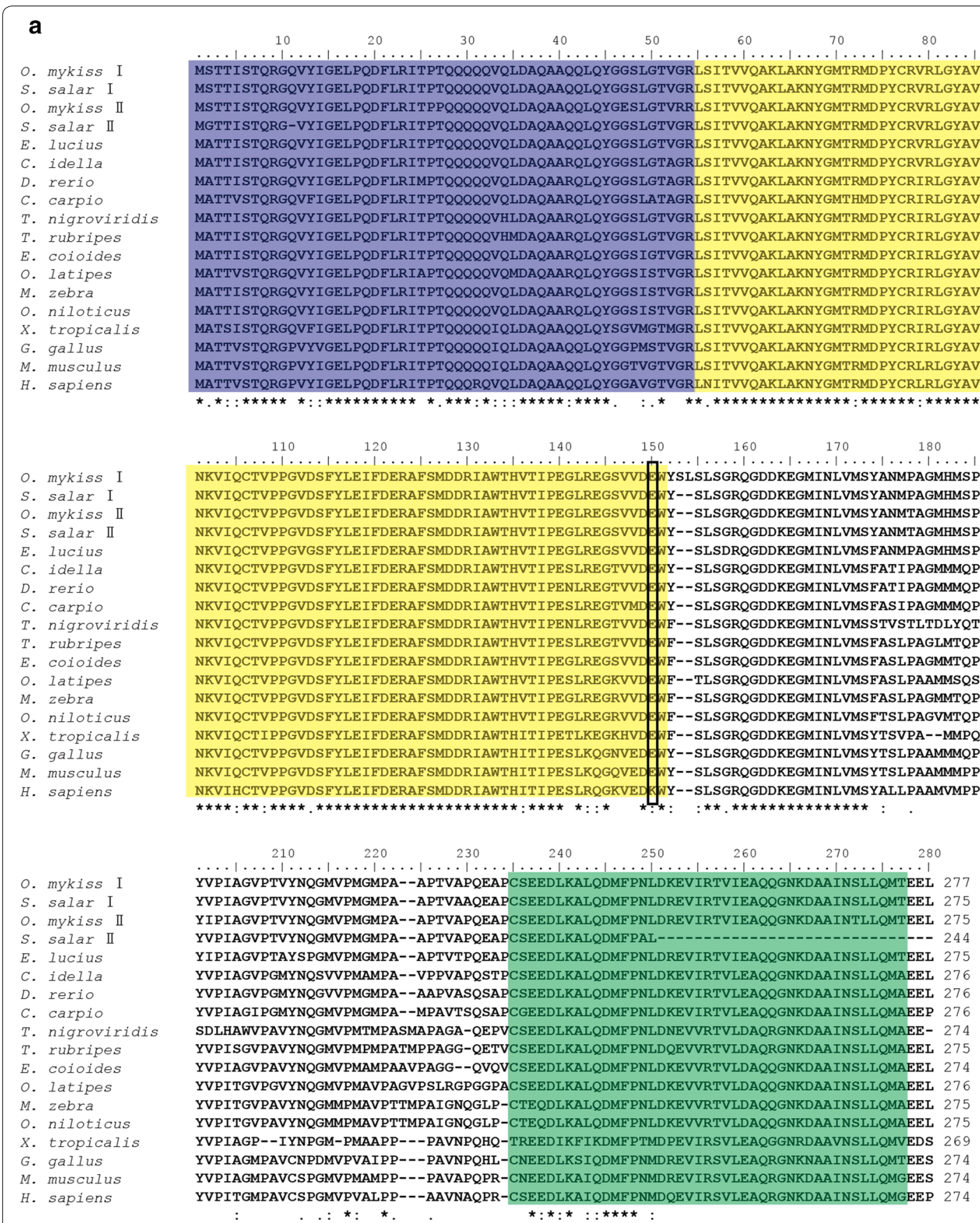

b TBD

Fig. 1 Multiple alignment and schematic representation of Tollip. a Amino acid sequence alignment and functional domains of Tollip. The sequences were aligned by ClustalX 2.0. The identical amino acid residue is indicated in the asterisk (*); the predicted domains from SMART Server software have been indicated by colored boxes: the blue denotes the TBD (Tom1-binding domain), the yellow shows the C2 (conserved core 2) domain, the green indicates the CUE (coupling of ubiquitin to endoplasmic reticulum degradation) domain. The black box points the amino acid at position 150. The GenBank accession numbers of these sequences are listed in Additional file 1: Table S1. b Schematic representation of the structural domains of Tollip. The predicted domains from SMART Server software are indicated by colored boxes as shown in Fig. 1a, while other regions are shaded in grey color. The asterisk $\left(^{*}\right)$ represent the amino acid at the position 150 


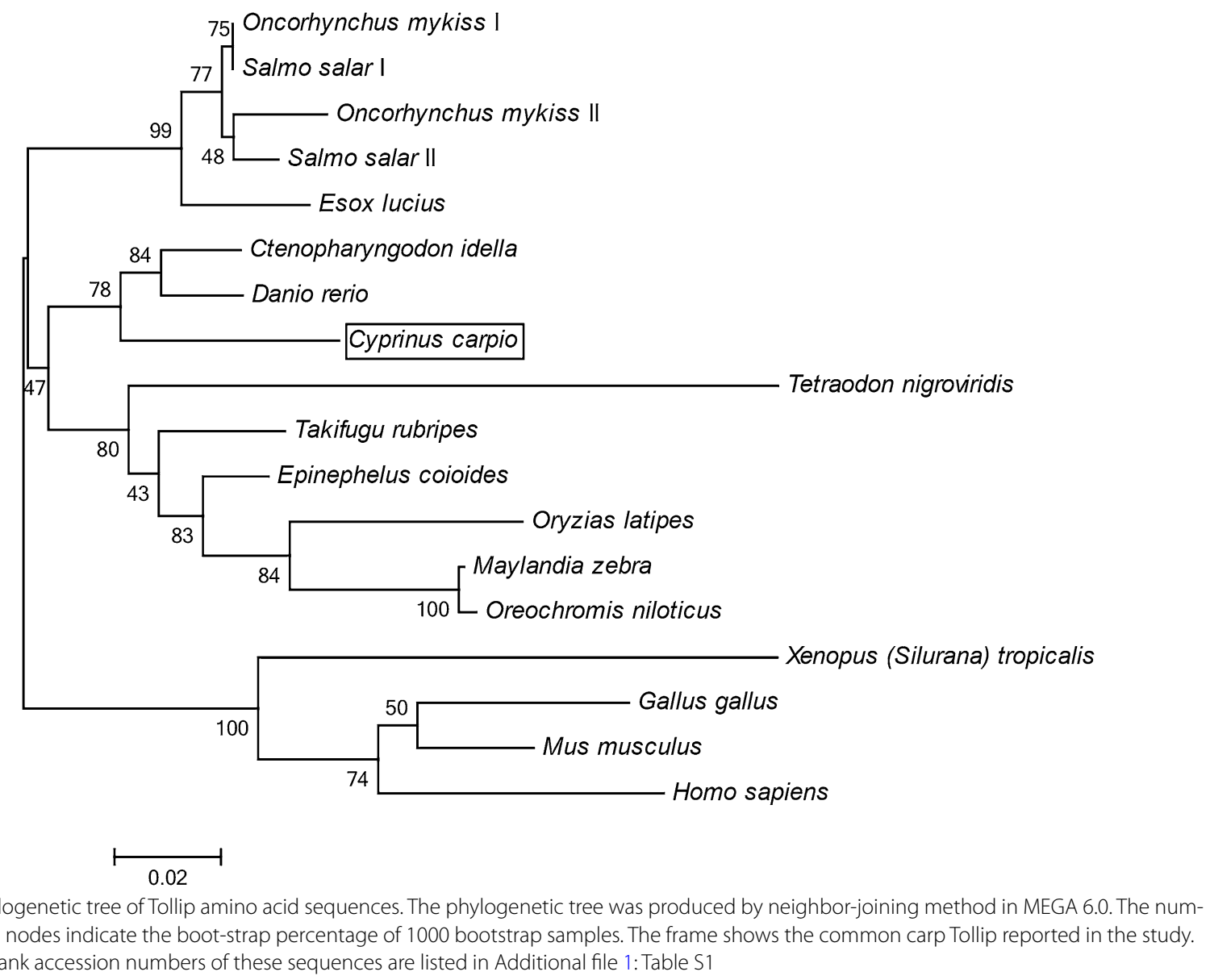

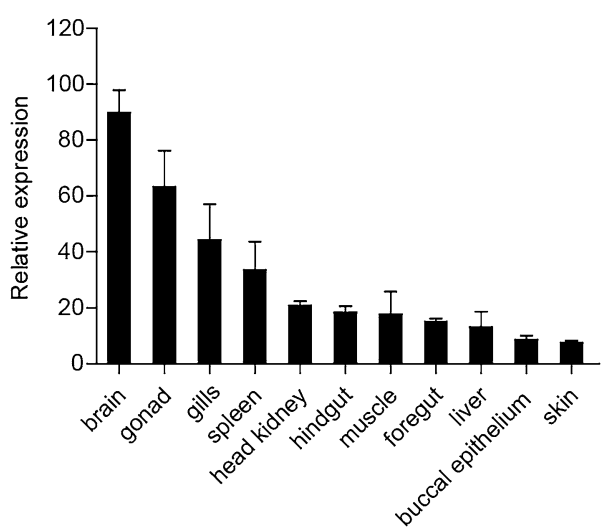

Fig. 3 Tissue expression of CcTollip in normal common carp. The CcTollip transcripts in the spleen, head kidney, foregut, hindgut, skin, gills, buccal epithelium, liver, muscle, gonad and brain of the common carp were detected by real-time PCR. 40 S ribosomal protein S11 in each tissue was amplified as internal control

\section{Discussion}

Tollip is an important regulator in TLRs mediating innate immune response. In this study, Tollip was isolated from common carp, and the role of CcTollip was investigated after stimulation with $V$. anguillarum and poly(I:C).

Structural analysis revealed that $C c$ Tollip contained a conserved TBD, C2 and CUE domain. Tollip can interact with Tom 1 and participate in the ubiquitination pathway through the TBD and CUE domain (Yamakami et al. 2003). CcTollip shared the same domains with other species, which suggested that CcTollip played the similar role as the other species Tollip did. Li et al. reported that overexpression of Tollip inhibited NF- $\mathrm{kB}$ reporter gene transcription in human monocytic THP-1 cells, and a point mutation of the lysine residue at position 150 to glutamic acid (K150E) could abolish this function of Tollip (Li et al. 2004). Although in fish and some other species, Tollip has a glutamic acid residue at this position. Rebl et al. reported that overexpression of the trout Tollip in HEK-293 cells also reduced TLR-mediated NF- $\mathrm{B}$ activation (Rebl et al. 2011), suggesting that the $C 2$ domain is essential in the function of Tollip to inhibit the activation of NF- $\mathrm{kB}$ pathway, although $\mathrm{C} 2$ domain in fish Tollip has different key amino acid residue compared with human. 

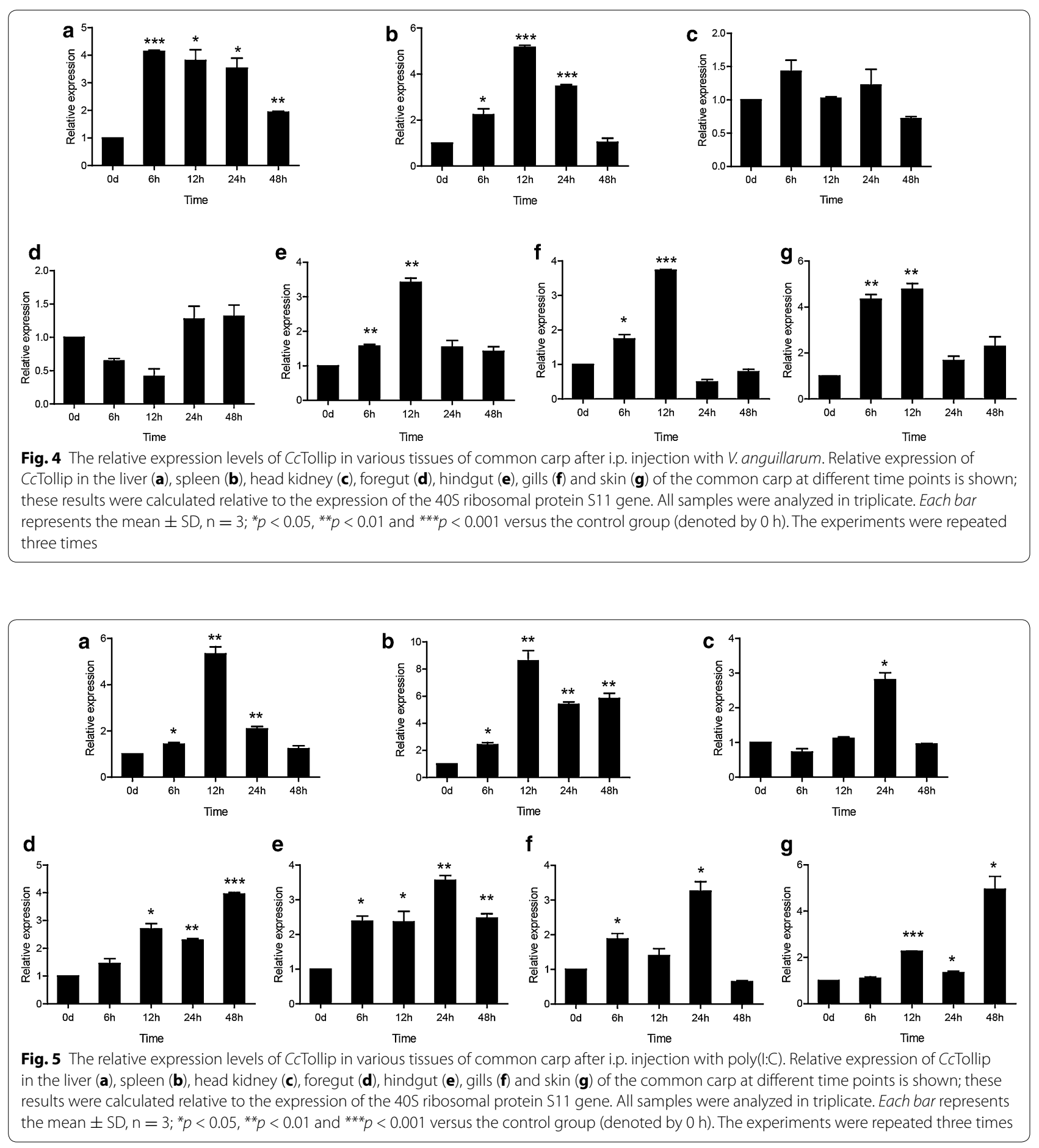

From the multiple sequence alignment, the CcTollip shared the highest similarity with the Tollip of zebrafish (93.8\%) and grass carp (93.1\%) (Additional file 3: Table S2). Phylogenetic tree showed that the CcTollip was clustered with other bony fish Tollip and it was most closely related to the grass carp and zebrafish Tollip
(Fig. 2). Furthermore, in the tree, the Tollip of salmonid fish divided into Tollip I and Tollip II, while the common carp only had one kind of Tollip, which was similar to other cyprinid fish.

The Tollip expression analysis has been investigated in several species, it is found that Tollip is ubiquitously 

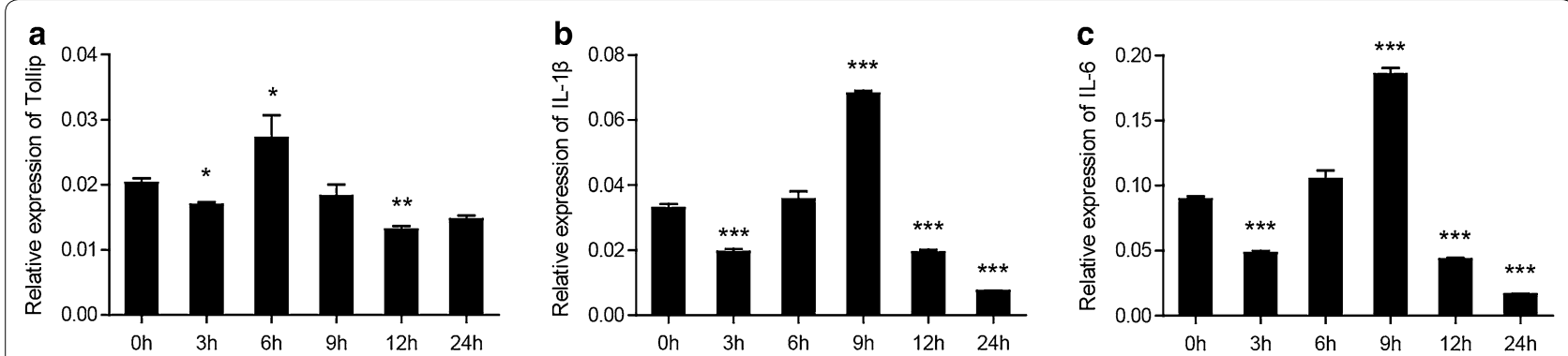

Fig. 6 Expression patterns of CCTollip, IL-1 $\beta$ and IL-6 gene induced by LPS in HKLs. a Induction expression of CcTollip by LPS. b Induction expression of IL-1 $\beta$ by LPS. $\mathbf{c}$ Induction expression of IL- 6 by LPS. Three groups of HKLs were treated with LPS for 3, 6, 9, 12 and $24 \mathrm{~h}$. Error bars represent the mean \pm SD obtained by measuring each sample three times from three independent experiments. The shown data have been normalized to $40 \mathrm{~S}$ ribosomal protein $\mathrm{s} 11$ gene. The experiments were repeated three times

expressed in many tissues or organs (Sandor and Buc 2005; Gunthner et al. 2013; Nishimura and Naito 2005; Lv et al. 2012; Rebl et al. 2008; Li et al. 2015). In this study, CcTollip was constitutively expressed in all tissues tested and it was highly expressed in brain of common carp. The previous studies have shown that interleukin-1 receptor type I (IL-1RI) and recruiting a signaling core complex consisting of the myeloid differentiation primary response protein 88 (MyD88) are differently distributed in the hippocampus and in the subcellular compartments of primary hippocampal neurons, suggesting that the members of IL-1R cascade participate in the neuronal signaling pathway (Gardoni et al. 2011). Tollip as a member of IL-1R signaling pathway may have a high expression in brain. The distribution of grouper Tollip confirmed our observation (Wei et al. 2015).

Tollip was reported to have the negatively regulatory function in mammalian (Burns et al. 2000; Rebl et al. 2008), while its expression was up-regulated in viral infected trout (Rebl et al. 2008) and grass carp (Huang et al. 2012), which relates to that the up-regulation of Tollip in fish may counteract the infection-related proinflammatory activation of the innate immune system and protect against pathological effects (Rebl et al. 2010). In the present study, we found that the expression of CcTollip was also up-regulated in many tissues of common carp after bacteria and poly(I:C) challenge. Spleen is one of the most important immune organs, in which there are plenty of lymphocytes, granulocytes and monocytes (Chen et al. 2013; Lieschke and Trede 2009). In this study, after injection with $V$. anguillarum and poly(I:C), the change of $C c$ Tollip expression level in the spleen of common carp was highest, which indicated that Tollip might play an important immune role in spleen.

The liver is the main source of acute-phase proteins (Baumann and Gauldie 1994; Nazemi et al. 2014) and has a unique vascular system receiving the majority of the blood supply faces continuous exposure to foreign pathogens and commensal bacterial products which could trigger TLRs signaling (Nakamoto and Kanai 2014). At the same time, the occurring of antiinflammatory response could avoid the injury of liver (Nakamoto and Kanai 2014). Thus, the expression of CcTollip in liver of common carp was significantly up-regulated after pathogen infection. However, the expression level of Tollip in head kidney and foregut had no change after stimulation with $V$. anguillarum. The previous study in Aeromonas salmonicida Infection Rainbow Trout confirmed the pronounced expression of $C c$ Tollip in liver and the unchanged expression in head kidney (Brietzke et al. 2015). Furthermore, we examined the expression of Tollip and proinflammatory cytokines. It was found that the mRNA level of Tollip, IL- $1 \beta$, and IL- 6 was up-regulated in HKLs, suggesting that there may be a correlation between Tollip and proinflammatory cytokines. The mechanism of the relationship between Tollip and proinflammatory cytokines in common carp need to be further investigated.

Tollip was reported to play an important role in epithelium-mediated cytolysis in pathogen clearance (Huang et al. 2012). And increased Tollip concentration was found in human intestinal cells, which was hypothesized to be a result of continuous exposure to the intestinal microflora (Melmed et al. 2003; Cario and Podolsky 2005). So the CcTollip transcript was significantly upregulated in gut, skin and gills, which were the sites of potential pathogen entry.

Interestingly, different from the tissues above, the expression level of $C c$ Tollip in head kidney and foregut had no change after infection with $V$. anguillarum (Fig. 4c, d). Thus, CcTollip may have multiple functions in common carp, and further studies on the function of CcTollip need to be done. 


\section{Conclusion}

In this study, we described the identification of $C c$ Tollip and the results suggested that $C c$ Tollip might play a role in the immune system of common carp, which established a basis for further examination of the $\mathrm{Cc}$ Tollip function. However, further investigation is needed to explore the antibacterial and antiviral mechanisms, which might be helpful in the development of new methods for preventing infections in common carp.

\section{Additional files}

Additional file 1: Table S1. GeneBank accession numbers of Tollip used in this study.

Additional file 2: Fig. S1. Nucleotide and deduced amino acid sequences of CcTollip. The nucleotide sequence, which encodes amino acid of Tollip is shown by capital, and amino acid sequence is shown below the nucleotide sequence. $5^{\prime}$ - and $3^{\prime}$-untranslated region are shown in lower case. The putative polyadenylation site (attaaa) is shown in bold.

Additional file 3: Table S2. Percent identity of Tollip between common carp and other species.

\section{Abbreviations}

Tollip: Toll interacting protein; V. anquillarum: Vibrio anguillarum; TLR: Toll-like receptor; PRR: pattern recognition receptor; NLR: NOD-like receptor; RLR: RIG-I-like receptor; RACE: rapid amplification of CDNA ends; ORF: open reading frame; TBD: Tom1-binding domain; C2: conserved core domain 2; CUE: coupling of ubiquitin to endoplasmic reticulum degradation.

\section{Authors' contributions}

Conceived and designed the experiments: LA and GY. Performed the experiments: SS and LW. Analyzed the data: SS, LW, FZ and YZ. Wrote the paper: SS, LW, LA and GY. All authors read and approved the final manuscript.

\section{Acknowledgements}

This work was supported by Shandong Provincial Natural Foundation of China under Grant ZR2014CQ051.

\section{Competing interests}

The authors declare that they have no competing interests.

Received: 25 September 2015 Accepted: 5 May 2016

Published online: 17 May 2016

\section{References}

Baumann H, Gauldie J (1994) The acute phase response. Immunol Today 15(2):74-80. doi:10.1016/0167-5699(94)90137-6

Brietzke A, Korytar T, Jaros J, Kollner B, Goldammer T, Seyfert HM, Rebl A (2015) Aeromonas salmonicida infection only moderately regulates expression of factors contributing to toll-like receptor signaling but massively activates the cellular and humoral branches of innate immunity in rainbow trout (Oncorhynchus mykiss). J Immunol Res 2015:901015. doi:10.1155/2015/901015

Brissoni B, Agostini L, Kropf M, Martinon F, Swoboda V, Lippens S, Everett H, Aebi N, Janssens S, Meylan E, Felberbaum-Corti M, Hirling H, Gruenberg J, Tschopp J, Burns K (2006) Intracellular trafficking of interleukin-1 receptor I requires Tollip. Curr Biol 16(22):2265-2270. doi:10.1016/j.cub.2006.09.062

Burns K, Clatworthy J, Martin L, Martinon F, Plumpton C, Maschera B, Lewis A, Ray K, Tschopp J, Volpe F (2000) Tollip, a new component of the IL-1RI pathway, links IRAK to the IL-1 receptor. Nat Cell Biol 2(6):346-351. doi:10.1038/35014038
Cario E, Podolsky DK (2005) Intestinal epithelial TOLLerance versus inTOLLerance of commensals. Mol Immunol 42(8):887-893. doi:10.1016/j. molimm.2004.12.002

Chen X, Wang Q, Yang C, Rao Y, Li Q, Wan Q, Peng L, Wu S, Su J (2013) Identification, expression profiling of a grass carp TLR8 and its inhibition leading to the resistance to reovirus in CIK cells. Dev Comp Immunol 41(1):82-93. doi:10.1016/j.dci.2013.04.015

Ciarrocchi A, D'Angelo R, Cordiglieri C, Rispoli A, Santi S, Riccio M, Carone S, Mancia AL, Paci S, Cipollini E, Ambrosetti D, Melli M (2009) Tollip is a mediator of protein sumoylation. PLoS ONE 4(2):e4404. doi:10.1371/journal.pone.0004404

Didierlaurent A, Brissoni B, Velin D, Aebi N, Tardivel A, Kaslin E, Sirard JC, Angelov G, Tschopp J, Burns K (2006) Tollip regulates proinflammatory responses to interleukin-1 and lipopolysaccharide. Mol Cell Biol 26(3):735-742. doi:10.1128/MCB.26.3.735-742.2006

Engelsma MY, Stet RJ, Schipper H, Verburg-van Kemenade BM (2001) Regulation of interleukin 1 beta RNA expression in the common carp, Cyprinus carpio L. Dev Comp Immunol 25(3):195-203

Gardoni F, Boraso M, Zianni E, Corsini E, Galli CL, Cattabeni F, Marinovich M, Di Luca M, Viviani B (2011) Distribution of interleukin-1 receptor complex at the synaptic membrane driven by interleukin-1 beta and NMDA stimulation. J Neuroinflammation 8(1):14. doi:10.1186/1742-2094-8-14

Gunthner R, Kumar VR, Lorenz G, Anders HJ, Lech M (2013) Pattern-recognition receptor signaling regulator $\mathrm{mRNA}$ expression in humans and mice, and in transient inflammation or progressive fibrosis. Int J Mol Sci 14(9):18124-18147. doi:10.3390/ijms140918124

Huang R, Lv J, Luo D, Liao L, Zhu Z, Wang Y (2012) Identification, characterization and the interaction of Tollip and IRAK-1 in grass carp (Ctenopharyngodon idellus). Fish Shellfish Immunol 33(3):459-467. doi:10.1016/j. fsi.2012.05.025

Joerink M, Ribeiro CM, Stet RJ, Hermsen T, Savelkoul HF, Wiegertjes GF (2006) Head kidney-derived macrophages of common carp (Cyprinus carpio L.) show plasticity and functional polarization upon differential stimulation. J Immunol 177(1):61-69

Katoh Y, Shiba Y, Mitsuhashi H, Yanagida Y, Takatsu H, Nakayama K (2004) Tollip and Tom1 form a complex and recruit ubiquitin-conjugated proteins onto early endosomes. J Biol Chem 279(23):24435-24443. doi:10.1074/ jbc.M400059200

Li T, Hu J, Li L (2004) Characterization of Tollip protein upon Lipopolysaccharide challenge. Mol Immunol 41(1):85-92. doi:10.1016/j. molimm.2004.03.009

Li H, Zhang F, Guo H, Zhu Y, Yuan J, Yang G, An L (2013) Molecular characterization of hepcidin gene in common carp (Cyprinus carpio L.) and its expression pattern responding to bacterial challenge. Fish Shellfish Immunol 35(3):1030-1038. doi:10.1016/j.fsi.2013.07.001

Li H, Guo H, Shan S, Qi C, An L, Yang G (2014) Characterization and expression pattern of a novel beta-defensin in common carp (Cyprinus carpio L.): implications for its role in mucosal immunity. Biosci Biotechnol Biochem 78(3):430-437. doi:10.1080/09168451.2014.885830

Li YW, Wang Z, Mo ZQ, Li X, Luo XC, Dan XM, Li AX (2015) Grouper (Epinephelus coioides) MyD88 and Tollip: intracellular localization and signal transduction function. Fish Shellfish Immunol 42(1):153-158. doi:10.1016/j. fsi.2014.10.041

Lieschke GJ, Trede NS (2009) Fish immunology. Curr Biol 19(16):R678-R682. doi:10.1016/j.cub.2009.06.068

Liu MW, Wang YH, Qian CY, Li H (2014a) Xuebijing exerts protective effects on lung permeability leakage and lung injury by upregulating Toll-interacting protein expression in rats with sepsis. Int J Mol Med 34(6):1492-1504. doi:10.3892/ijmm.2014.1943

Liu Y, Jiang XL, Liu Y, Jiang DS, Zhang Y, Zhang R, Chen Y, Yang Q, Zhang XD, Fan GC, Li H (2014b) Toll-interacting protein (Tollip) negatively regulates pressure overload-induced ventricular hypertrophy in mice. Cardiovasc Res 101(1):87-96. doi:10.1093/cvr/cvt232

Lv J, Huang R, Li H, Luo D, Liao L, Zhu Z, Wang Y (2012) Cloning and characterization of the grass carp (Ctenopharyngodon idella) Toll-like receptor 22 gene, a fish-specific gene. Fish Shellfish Immunol 32(6):1022-1031. doi:10.1016/j.fsi.2012.02.024

Maillard MH, Bega H, Uhlig HH, Barnich N, Grandjean T, Chamaillard M, Michetti P, Velin D (2014) Toll-interacting protein modulates colitis susceptibility in mice. Inflamm Bowel Dis 20(4):660-670. doi:10.1097/ MIB.0000000000000006 
Melmed G, Thomas LS, Lee N, Tesfay SY, Lukasek K, Michelsen KS, Zhou Y, Hu B, Arditi M, Abreu MT (2003) Human intestinal epithelial cells are broadly unresponsive to Toll-like receptor 2-dependent bacterial ligands: implications for host-microbial interactions in the gut. J Immunol 170(3):1406-1415

Mukherjee S, Biswas T (2014) Activation of TOLLIP by porin prevents TLR2-associated IFN-gamma and TNF-alpha-induced apoptosis of intestinal epithelial cells. Cell Signal 26(12):2674-2682. doi:10.1016/j. cellsig.2014.08.009

Nakamoto N, Kanai T (2014) Role of toll-like receptors in immune activation and tolerance in the liver. Front Immunol 5:221. doi:10.3389/ fimmu.2014.00221

Nazemi S, Aalbaek B, Kjelgaard-Hansen M, Safayi S, Klaerke DA, Knight CH (2014) Expression of acute phase proteins and inflammatory cytokines in mouse mammary gland following Staphylococcus aureus challenge and in response to milk accumulation. J Dairy Res 81(4):445-454. doi:10.1017/ S0022029914000454

Nishimura M, Naito S (2005) Tissue-specific mRNA expression profiles of human toll-like receptors and related genes. Biol Pharm Bull 28(5):886-892

Rebl A, Hoyheim B, Fischer U, Kollner B, Siegl E, Seyfert HM (2008) Tollip, a negative regulator of TLR-signalling, is encoded by twin genes in salmonid fish. Fish Shellfish Immunol 25(1-2):153-162. doi:10.1016/j. fsi.2008.04.002

Rebl A, Goldammer T, Seyfert HM (2010) Toll-like receptor signaling in bony fish. Vet Immunol Immunopathol 134(3-4):139-150. doi:10.1016/j. vetimm.2009.09.021

Rebl A, Rebl H, Liu S, Goldammer T, Seyfert HM (2011) Salmonid Tollip and MyD88 factors can functionally replace their mammalian orthologues in TLR-mediated trout SAA promoter activation. Dev Comp Immunol 35(1):81-87. doi:10.1016/j.dci.2010.08.012

Sandor F, Buc M (2005) Toll-like receptors. II. Distribution and pathways involved in TLR signalling. Folia Biol (Praha) 51(6):188-197
Shibolet O, Podolsky DK (2007) TLRs in the Gut. IV. Negative regulation of Toll-like receptors and intestinal homeostasis: addition by subtraction. Am J Physiol Gastrointest Liver Physiol 292(6):G1469-G1473. doi:10.1152/ ajpgi.00531.2006

Shimizu M, Oguro-Ando A, Ohoto-Fujita E, Atomi Y (2014) Toll-interacting protein pathway: degradation of an ubiquitin-binding protein. Methods Enzymol 534:323-330. doi:10.1016/B978-0-12-397926-1.00018-4

Wei J, Xu M, Chen X, Zhang P, Li P, Wei S, Yan Y, Qin Q (2015) Function analysis of fish Tollip gene in response to virus infection. Fish Shellfish Immunol 47(2):807-816. doi:10.1016/j.fsi.2015.10.008

Yamakami M, Yokosawa H (2004) Tom1 (target of Myb 1) is a novel negative regulator of interleukin-1- and tumor necrosis factor-induced signaling pathways. Biol Pharm Bull 27(4):564-566

Yamakami M, Yoshimori T, Yokosawa H (2003) Tom1, a VHS domain-containing protein, interacts with tollip, ubiquitin, and clathrin. J Biol Chem 278(52):52865-52872. doi:10.1074/jbc.M306740200

Yang G, Guo H, Li H, Shan S, Zhang X, Rombout JH, An L (2014) Molecular characterization of LEAP-2 CDNA in common carp (Cyprinus carpio L.) and the differential expression upon a Vibrio anguillarum stimulus; indications for a significant immune role in skin. Fish Shellfish Immunol 37(1):22-29. doi:10.1016/j.fsi.2014.01.004

Zhang G, Ghosh S (2002) Negative regulation of toll-like receptor-mediated signaling by Tollip. J Biol Chem 277(9):7059-7065. doi:10.1074/jbc. M109537200

Zhang YB, Gui JF (2012) Molecular regulation of interferon antiviral response in fish. Dev Comp Immunol 38(2):193-202. doi:10.1016/j.dci.2012.06.003

Zhang J, Kong X, Zhou C, Li L, Nie G, Li X (2014) Toll-like receptor recognition of bacteria in fish: ligand specificity and signal pathways. Fish Shellfish Immunol 41(2):380-388. doi:10.1016/j.fsi.2014.09.022

Zhang R, Li R, Wang J, Wang S, Zhang M, Hu X, Zhang L, Wang S, Wang R, Bao $Z$ (2015) Identification, characterization and expression profiling of the Tollip gene in Yesso scallop (Patinopecten yessoensis). Genes Genet Syst 90(2):99-108. doi:10.1266/ggs.90.99

\section{Submit your manuscript to a SpringerOpen ${ }^{\odot}$ journal and benefit from:}

- Convenient online submission

- Rigorous peer review

- Immediate publication on acceptance

- Open access: articles freely available online

- High visibility within the field

- Retaining the copyright to your article

Submit your next manuscript at springeropen.com 